\section{More Than Metaphor: Online Resources for Teaching Cancer Biology}

Amy J. Hawkins* and Louisa A. Stark

Genetic Science Learning Center, University of Utah, Salt Lake City, UT 84102

C ancer humbles us through its nearly universal capacity to impact our lives. As such, the phenomenon of cancer provides educators with a unique opportunity to galvanize attention. Students who might not otherwise give cell biology or genetics a second glance nevertheless are driven to cancer biology with questions: "What causes cancer?," "How many people get cancer?," "When will we cure cancer?" Given the lifetime prevalence of cancer and its cultural pervasiveness, cancer biology is the window through which many students first encounter compelling reasons to engage with life science. Not only does a cancer biology curriculum provide an opportunity to integrate virtually every discipline within the life sciences (Shuster and Peterson, 2009), a comprehensive view of the subject is multiscalar, incorporating information from the molecular level, the whole organism, and the social practice of medicine, including health disparities (Weber, 2016). Cancer biology also engages students because it continues to draw controversy; some of our highest elected officials question the established connection between smoking tobacco and lung cancer (Matthews, 2016), and popular media personalities perpetuate myths about commonly used herbicides and cancer (Hari, 2016). It is important that we equip students of biology with the ability to critically sift through these and other claims about the causes and effective treatments of cancer.

The internet contains an overwhelming amount of information about cancer, but sifting through these resources is an immense and time-consuming task. In this Feature, we highlight free online resources that may be useful for science educators teaching cancer biology to high school and undergraduate students.

\section{THE STORY OF CANCER: THE EMPEROR OF ALL MALADIES}

In 2015, PBS aired The Story of Cancer: The Emperor of All Maladies, a 6-hour documentary produced and directed by Ken Burns, Barak Goodman, and a team of directors and writers, based on the Pulitzer Prize-winning book The Emperor of All Maladies: A Biography of Cancer by Siddhartha Mukherjee (2010). The documentary was divided into three 2-hour episodes, and all are freely available but require an internet connection, as they cannot be downloaded for viewing offline (http://cancerfilms.org/media -gallery). Both the book and documentary provide a history of cancer research beginning with its first mention in recorded history by ancient Egyptian physicians and continuing through the first successful surgical treatments for cancer, the first chemotherapy-induced remission in childhood leukemia, and some of the cutting-edge treatments in use today, including immunotherapy and targeted therapies. The narrative interweaves the progress of research with emotional stories about individual patients, passionate political advocates, and campaigns to fund research. Given the strong emotional and personal nature of its subject, viewing the film may be difficult for some viewers, but the material is otherwise suitable for both high school and college students.

The companion website for the film contains additional content and short excerpts from the documentary, presenting key material in a useful form for classrooms. This website contains "The History of Cancer," an interactive timeline separated into Before 1940, 1940-1970, 1970-Today, and Tomorrow (http://cancerfilms.org/timeline). Each portion of the timeline highlights the major themes by showcasing primary
CBE Life Sci Educ September 1, 2017 16:fe5 DOI:10.1187/cbe.17-05-0087

*Address correspondence to: Amy J. Hawkins (amy.j.hawkins(autah.edu).

(C) 2017 A. J. Hawkins and L. A. Stark. CBE-Life Sciences Education ( 2017 The American Society for Cell Biology. This article is distributed by The American Society for Cell Biology under license from the author(s). It is available to the public under an Attribution-Noncommercial-Share Alike 3.0 Unported Creative Commons License (http://creativecommons.org/licenses/ by-nc-sa/3.0).

"ASCB ${ }^{\circledR "}$ and "The American Society for Cell Biology ${ }^{\circledR "}$ are registered trademarks of The American Society for Cell Biology. 


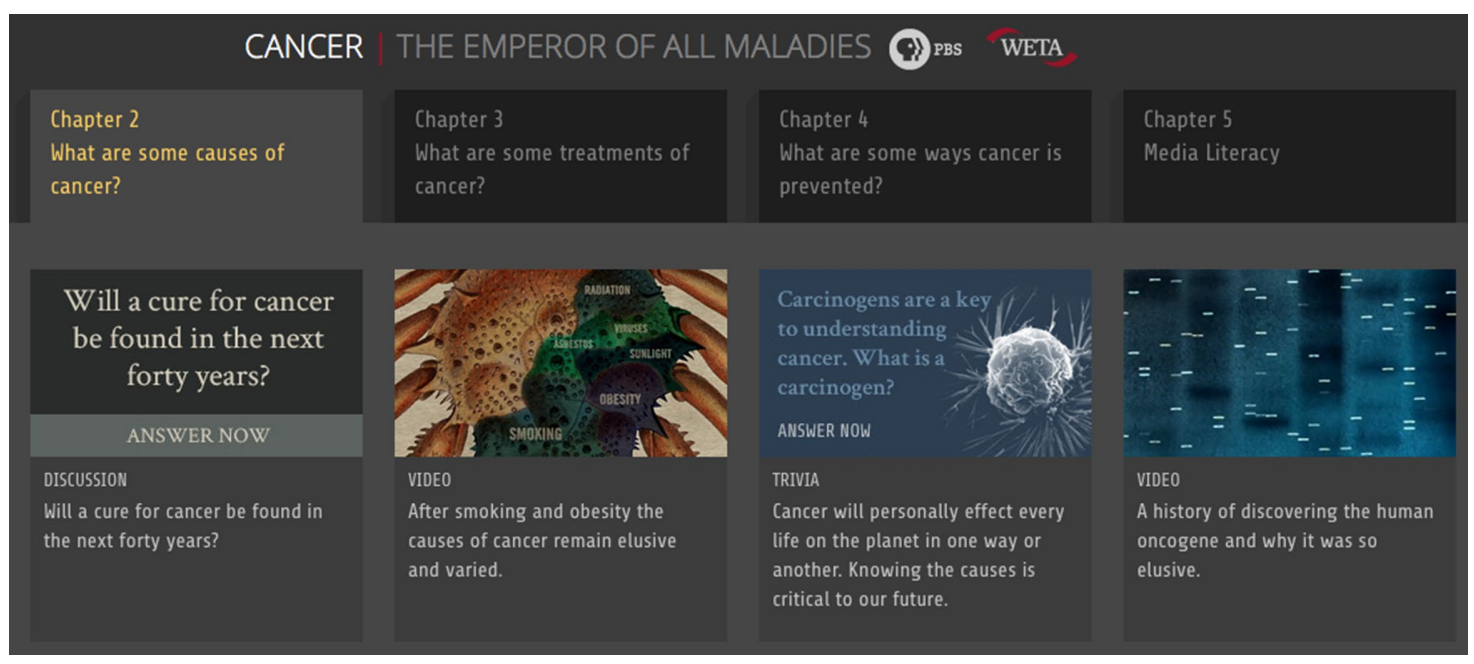

FIGURE 1. The Classroom section of website designed to accompany the documentary The Emperor of All Maladies provides a customizable way to use short clips from the documentary film along with lesson plans and several other interactive features (http://cancerfilms .org/classroom).

research documents, works of cultural importance that raised awareness of cancer, political figures, the advent of particular diagnostic procedures, campaigns to raise research funds, and findings of landmark clinical trials. The classroom section of the website separates materials into seven different chapters: 1) "What Is Cancer?," 2) "What Are Some Causes of Cancer?," 3) "What Are Some Treatments of Cancer?," 4) "What Are Some Ways Cancer Is Prevented?," 5) "Media Literacy," 6) "Scientific Method," and 7) "Women in Science." Each chapter includes several (sometimes redundant) 1- to 5-minute video clips from the documentary, and some chapters include additional materials such as trivia questions or infographics (http:// cancerfilms.org/classroom; Figure 1). Users can register a profile with the website to select and order content modules, creating a customizable classroom playlist. Chapters 1, 5, 6, and 7 also include lesson plans that may be downloaded as PDFs. Each plan is made up of a series of class discussion questions designed to accompany the short video clips from the film. Each plan also notes the educational standards it addresses, including those from Benchmarks for Science Literacy and the Next Generation Science Standards (American Association for the Advancement of Science, 1993; NGSS Lead States, 2013).

\section{iBIOLOGY}

The iBiology website (www.ibiology.org) hosts more than 300 seminars and short talks by the world's leading scientists. After registering as an educator by submitting an official Web page with your name and professional affiliation (allow at least a week for your credentials to be reviewed and verified by the website, which helps to ensure that only educators can access course questions and answer rubrics), users can view a special category of resources: iBioSeminars Teaching Tools; assessments for iBioEducation talks, lectures, and short clips; and course materials for the Cell Biology Flipped Course (www .ibiology.org/ibioeducation/educator-resources.html). The Cell Biology Flipped Course is likely to be of particular interest to undergraduate teachers. It was designed by Professor Jonathan
Scholey and initially offered to senior undergraduate biology majors in Spring 2013 at the University of California, Davis. The 9-week course is organized around videos of PowerPoint-enhanced lectures by scientific experts in their respective fields. Each lecture, which ranges from $\sim 28$ minutes to a twopart lecture (each part is approximately 1 hour long), can be downloaded and has optional closed captioning. The course covers nine topic areas: origin of life, organization of cytoplasm, G-proteins, vesicle trafficking, cell motility, cytoskeletal motor proteins, cell division, protein kinases, and the cell cycle. Each topic also includes a written overview of the lecture, a short biography of the speaker, an assignment with a suggested grading rubric, and quiz questions and answers.

iBiology also provides educator resources designed to accompany the lectures (www.ibiology.org/ibioeducation/educator -resources/teaching-tools-for-seminars.html), several of which are particularly relevant for teaching cancer biology. For example, J. Michael Bishop, who shared the 1989 Nobel Prize for discovering human oncogenes, recorded a three-part lecture series suitable for advanced high school, undergraduate, and graduate students: "Part I: Cancer: The Rise of the Genetic Paradigm" (28:36 minutes); "Part II: Exploiting the Cancer Genome" (43:32 minutes); and "Part III: The Cancer Genome and Therapeutics" (40:54 minutes). Additional resources include a transcript of each lecture, lists of keywords and terms, detailed lecture notes, discussion questions, and recommended further reading (references from peer-reviewed scientific literature). For those looking for shorter video resources, Bishop's and other lectures are excerpted in seven shorter video clips, each less than 5 minutes long (www.ibiology.org/ibioeducation/ educator-resources/teaching-tools-for-seminars/short-clips -part-4.html\#Bishop).

Other relevant iBiology seminars may not include additional teaching materials, but they can be browsed via subject (www .ibiology.org/ibioseminars.html). Several of the lectures organized under the topic headings of Cancer \& Medicine, Cell Biology, and Genetics \& Gene Regulation are appropriate for 


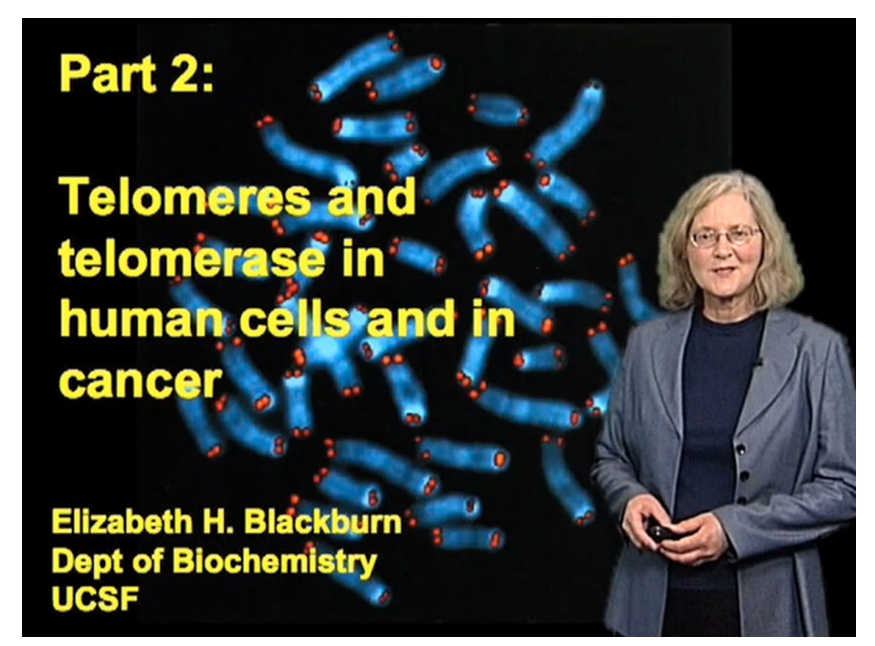

FIGURE 2. The iBiology website hosts a variety of lectures by cancer researchers, including a three-part lecture series by Nobel laureate Elizabeth Blackburn on telomeres and telomerase (www .ibiology.org/ibioseminars/genetics-gene-regulation/elizabeth -blackburn-part-2.html).

undergraduate or graduate-level cancer biology courses (www .ibiology.org/ibioseminars/genetics-gene-regulation/elizabeth -blackburn-part-2.html; Figure 2).

Another section of the iBiology website is specifically designed to engage high school educators by providing examples of iBiology videos that align with the concepts and categories in Vision and Change's "Core Concepts and Competencies," Next Generation Science Standards, and Advanced Placement Biology standards (www.ibiology.org/ibioeducation/educator -resources/ibioeducation-science-standards-and-core-concepts -index.html). Several cell biology videos can be integrated into a cancer biology unit, and the organization of the Web page

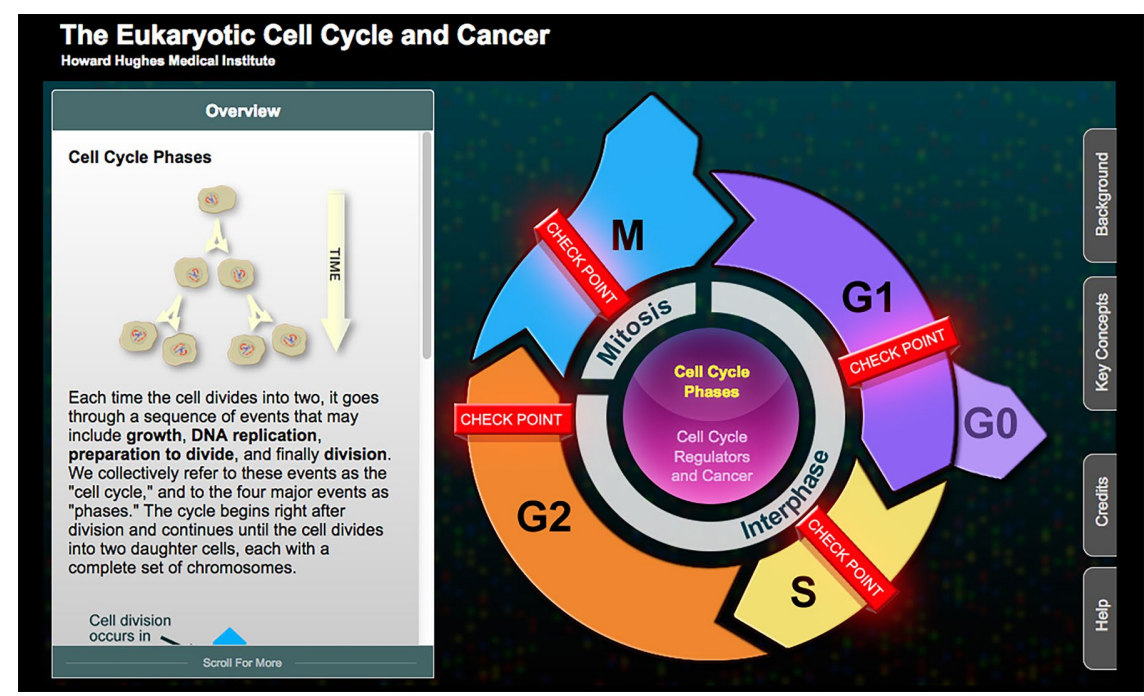

FIGURE 3. The Eukaryotic Cell Cycle and Cancer Click and Learn on the HHMI Biolnteractive site supports exploration of cell division, the phases of the cell cycle, cell cycle regulators, and how mutations in these regulators can lead to cancer (www.hhmi.org/ biointeractive/eukaryotic-cell-cycle-and-cancer). Used with permission from the Howard Hughes Medical Institute. Copyright @ 2014. All rights reserved. suggests ways to further integrate a high school cancer biology unit into existing standards.

\section{HHMI BIOINTERACTIVE}

The HHMI BioInteractive website (www.hhmi.org/biointeractive) lists 39 resources related to cancer. These include videos (11), animations (nine), interactive media (three), images (two), three-dimensional (3D) models (five), and classroom resources (four); all resources can easily be found via the site's search function. Four of the videos (each slightly less than 60 minutes) are selected from the 2003 and 2013 Holiday Lectures on Science. In the two most recent, Charles L. Sawyers, M.D., of the Memorial Sloan Kettering Cancer Center, discusses the genetic basis for cancer and the development of new therapies targeted to specific types of tissues and gene mutations. Each lecture can be viewed online or downloaded as a MP4 file; a transcript is available as a PDF. Because educators are less likely to show a full lecture in class, BioInteractive also provides short videos clips from the lectures, including how DNA sequence technology improves cancer treatment, cancer as a genetic disease, and polyp removal. Additional videos are interviews with Sawyers and an undergraduate student in his lab. The short videos range in length from 36 seconds to $8: 32$ minutes and can be downloaded as HD or SD M4V or WMV files.

Animations from the lectures are also available as excerpts (26 seconds to 3:31 minutes). The topics include angiogenesis, vascular endothelial growth factor and its function, the p53 molecule and its potential use in fighting cancer, cancer in the intestinal epithelium, and how the drug Gleevec works. Each animation can be downloaded as a large or small MOV or WMV file. Because the animations were excerpted from the longer lectures, the "narration" is not professional quality. The Angiogenesis and Cancer and Cell Fate in the Intestinal Epithelium animations are available as downloadable MP4 files with Spanish dubbing.

Several Click and Learn interactive multimedia pieces allow students to explore on their own. Eukaryotic Cell Cycle and Cancer supports exploration of cell division, the phases of the cell cycle, cell cycle regulators, and how mutations in these regulators can lead to cancer (www .hhmi.org/biointeractive/eukaryotic-cell -cycle-and-cancer; Figure 3). Both English and Spanish versions are available. p53 Gene and Cancer illustrates the structure, function, and regulation of the p53 gene and its protein product. BCR-ABL: Cancer Protein Structure and Function begins with an overview of protein structure, enzymes, and kinases and then describes the role of BCR-ABL in chronic myeloid leukemia and development of drugs to treat this cancer. The interactives effectively incorporate text, images, animations, and video clips. Downloadable PDFs of worksheets are provided to guide students through each interactive, with overview and advanced versions for the first two interactives. 
The two images provide useful illustrations. The computer simulation Cancer Evolution uses color to powerfully illustrate the large number of mutations present in a tumor. In Reckless Growth, a slice of a fluorescently stained mouse intestine compares the differing cell organization in healthy and cancerous tissue.

Other unique resources include STL printing instructions for 3D models that can be produced on 3D printers or be viewed online. The models include: BCR-ABL: ABL Kinase Domain; Gleevec-Resistant BCR-ABL: ABL Kinase Domain; Imatinib (Gleevec); Dasatnib; and Adenosine Triphosphate (ATP).

The downloadable PDFs in "Cancer Discovery Activities" provide teacher and student materials for two activities. Both activities begin with students watching the short video Cancer as a Genetic Disease (8:32 minutes) and completing a worksheet. The Classifying Cancer Genes activity continues with students working in small groups, using subsets of the 139 Cancer Gene Cards to create posters classifying the genes by type and function and showing their locations on human chromosomes. In the Examining Cancer Patient Data activity, students work in small groups with cards showing mutations found in actual patients. They first compare and contrast the mutations found among patients with the same type of cancer and then within different tissues from the same patient. If the video is assigned as out-of-class work, the small group activities take 35-40 minutes. These activities facilitate student understanding of cancer as a complex, genetic disease. Both can be used with high school students, although the second activity is more appropriate for upper-level high school and lower-level undergraduate students. Additional resources include two readings and a poster.

\section{INSIDE CANCER}

The DNA Learning Center's “Inside Cancer" (www.insidecancer .org) provides a basic but comprehensive overview of cancer biology through a series of animated slideshows with audio files from notable leaders in the field of cancer research. Sections include Hallmarks of Cancer, Causes and Preventions, Diagnosis and Treatment, and Pathways to Cancer. The website was designed in 2006-2008, and thus contains some dated information in this rapidly moving field, but the basic information is largely still accurate and suitable for a first introduction to cancer biology. For example, the Hallmarks of Cancer section includes subsections on cancer cells growing uncontrollably, evading death, processing nutrients, becoming immortal, invading tissues, avoiding detection, and promoting mutations. In 2011, Hanahan and Weinberg expanded their initial description of "the six essential alterations in cell physiology that collectively dictate malignant growth," which they proposed in 2000, noting contributions that are not covered in the Hallmarks list, including those of the tumor microenvironment, tumor-promoting inflammation, and reprogramming of energy metabolism (Hanahan and Weinberg, 2000, 2011). This update is particularly useful for more advanced students. Of further interest to high school educators, the "Inside Cancer" content has been aligned to curriculum statements from the American
Association for the Advancement of Science's Project 2061 Benchmarks for Science Literacy and the National Academy of Sciences' National Science Education Standards (American Association for the Advancement of Science, 1993; National Research Council, 1996).

\section{OTHER RESOURCES}

Additional cell biology apps for Apple devices were reviewed for this journal in 2012, and many would still be relevant for use in teaching those aspects of cancer biology (Stark, 2012). The Cell Biology and Cancer high school curriculum supplement from the National Institutes of Health (https://science.education.nih .gov/HighSchool/CellBiologyAndCancer) has also been previously reviewed for this journal (Kalumuck and Doss, 2004). While the materials contain useful content, the online interactive activities from 1999 may require updating for current use.

The emotional and multidisciplinary nature of cancer may capture students' attention unlike any other area of biomedical science. We hope that, by disseminating these resources, we will help students engage with cancer biology and inspire curiosity about how to make progress against it.

\section{ACKNOWLEDGMENTS}

We thank Marshall Sundberg for critical comments and helpful suggestions on this Feature.

\section{REFERENCES}

American Association for the Advancement of Science. (1993). Benchmarks for science literacy. New York: Oxford University Press

Hanahan, D., \& Weinberg, R. A. (2000). The hallmarks of cancer. Cell, 100, 57-70.

Hanahan, D., \& Weinberg, R. A. (2011). Hallmarks of cancer: The next generation. Cell, 144, 646-674.

Hari, V. (2016). Monsanto is scrambling to bury this breaking story-Don't let this go unshared! FoodBabe, Retrieved November 15, 2016, from http:// foodbabe.com/2016/11/15/monsanto

Kalumuck, K., \& Doss, K. (2004). Review of: National Institutes of Health Curriculum Supplements: Human Genetic Variation and Cell Biology and Cancer, by Biological Sciences Curriculum Study and Videodiscovery; 1999; http://science.education.nih.gov/customers.nsf/highschool.htm. Cell Biology Education, 3, 152-154.

Matthews, D. (2016). Mike Pence claimed "smoking doesn't kill" as late as 2000. Vox, Retrieved November 10, 2016, from www.vox.com/policy -and-politics/2016/10/4/13164074/mike-pence-smoking-tobacco

Mukherjee, S. (2010). The emperor of all maladies: A biography of cancer. New York: Scribner.

National Research Council. (1996). National Science Education Standards Washington, DC: National Academy Press.

NGSS Lead States. (2013). Next Generation Science Standards: For states, by states. Retrieved July 28, 2017, from www.nextgenscience.org

Shuster, M., \& Peterson, K. (2009). Development, implementation, and assessment of a lecture course on cancer for undergraduates. CBE-Life Sciences Education, 8, 193-202.

Stark, L. (2012). Cell biology apps for Apple devices. CBE-Life Sciences Education, 11, 226-230.

Weber, C. (2016). Beyond the cell: Using multiscalar topics to bring interdisciplinarity into undergraduate cellular biology courses. CBE-Life Sciences Education, 15, es1. 